\title{
Management of fetal urinary tract anomalies detected by prenatal ultrasonography
}

\author{
R R TURNOCK AND R SHAWIS \\ Department of Urology, Alder Hey Children's Hospital, Liverpool
}

SUMMARY Over a three and a half year period 32 babies were referred with a urinary tract anomaly diagnosed by prenatal ultrasound. This diagnosis was subsequently confirmed in 19 infants by postnatal assessment. Three of 13 infants in whom the original diagnosis was incorrect were subsequently found to have intra-abdominal pathology but no urological anomaly, while the other 10 had lesions in the urinary tract but not those suggested prenatally. Nineteen of the 29 babies with urological abnormalities were clinically normal at birth; 20 underwent surgery. There were three deaths; two from a combination of renal and pulmonary failure secondary to posterior urethral valves, and a third (in an infant who had normal renal function) from diaphragmatic hernia and cardiac anomalies. Prenatal diagnosis was thought to have been of benefit in six patients, of probable benefit in 16, and of no benefit in seven.

Anomalies of the fetal urinary tract are particularly amenable to diagnosis by ultrasound examination in utero, partly because hydronephrotic and cystic lesions are readily detected by this imaging technique and also because the oligohydramnios resulting from severe fetal renal dysplasia or obstruction is itself a specific indication for maternal ultrasound scanning. ${ }^{1}$ As routine scanning of all pregnancies is becoming increasingly widespread, the number of these anomalies diagnosed prenatally will increase further. This diagnostic expertise has several implications for urological practice, and raises a number of therapeutic questions to which there are not always clear answers. These may be illustrated from our own experience.

\section{Patients and methods}

Between September 1979 and the end of 1983, 32 babies with a prenatal diagnosis of a urinary tract anomaly were referred to our unit. The number of these referrals has increased from four at the end of 1981 to 17 in 1983. In 29 of the infants the diagnosis was made in the third trimester and in the remaining three at around 16 weeks of gestation.

Referrals came from 11 separate obstetric units situated throughout the Merseyside and North Wales regions. Individual units differ in their policies but in general terms the routine ultrasound scanning of pregnant women is performed by trained technicians: if they detect any untoward features or if there is an obstetrical indication for the scan (for example oligohydramnios) a radiological opinion is sought.

In only one infant had there been prenatal intervention. Here, detection of infravesical obstruction at 32 weeks of gestation prompted an attempt at needle aspiration of the fetal bladder. This manoeuvre precipitated premature labour and the baby subsequently died (qv). Thirty of the patients were referred within one month of birth, 20 within the first week.

Initial ultrasound assessment to confirm the prenatal diagnosis was usually performed by the referring hospital. After referral an intravenous urogram was performed in all cases and further investigations were determined by the results of these preliminary studies.

\section{Results}

Diagnostic accuracy (Table 1). In 19 infants the prenatal diagnosis was confirmed precisely and in another 10 a urinary tract anomaly was confirmed, although it differed from that diagnosed prenatally. The remaining three infants did not have hydronephrosis but did have other non-urological intraabdominal pathology. These three will not be considered further.

Clinical presentation. Nineteen of the babies were asymptomatic, had no clinically detectable urologi- 
Table 1 Diagnostic accuracy of prental ultrasound

\begin{tabular}{lllr}
\hline Prenatal diagnosis & No & Postnatal diagnosis & No \\
\hline $\begin{array}{l}\text { Pelviureteric junction } \\
\text { obstruction }\end{array}$ & 24 & $\begin{array}{l}\text { Pelviureteric junction } \\
\text { obstruction } \\
\text { Megacalicosis }\end{array}$ & 12 \\
& & $\begin{array}{l}\text { Primary megaureter } \\
\text { Duplex kidney with } \\
\text { hydronephrosis }\end{array}$ & 2 \\
& & $\begin{array}{l}\text { Orthotopic ureterocele } \\
\text { with hydronephrosis }\end{array}$ & 1 \\
& & $\begin{array}{l}\text { Posterior urethral valves } \\
\text { Jejunal atresia }\end{array}$ & 1 \\
& & $\begin{array}{l}\text { Meconium peritonitis } \\
\text { Exomphalos }\end{array}$ & 1 \\
Multicystic or dysplastic \\
kidney
\end{tabular}

cal abnormality, and were free of urinary tract infection. Three infants with posterior urethral valves had obviously enlarged bladders and kidneys at birth. The affected kidney was palpable in a further seven infants with supravesical lesions (five with pelviureteric junction obstruction and two with multicystic kidneys). Two babies had other congenital anomalies - the first had an orthotopic ureterocele and a tracheo-oesophageal fistula, the second is described below. These other anomalies were not detected prenatally.

Outcome. There were three deaths in the series. Two infants with posterior urethral valves died from renal failure. The first (described above) was born prematurely at 32 weeks' gestation after an interventional manoeuvre and died at 4 days of age. The

Table 2 Details of treatment in 29 infants with a prenatal diagnosis of urinary tract anomaly

\begin{tabular}{lrl}
\hline Final diagnosis & No & Treatment \\
\hline Pelviureteric junction obstruction & 10 & Dismembered pyeloplasty \\
& 1 & Pyelolysis \\
Multicystic or dysplastic kidney & 2 & Conservative \\
& 3 & Nephrectomy \\
Megacalicosis & 1 & Conservative \\
Posterior urethral valves & 4 & Conservative \\
& 2 & Valves fulgurated \\
Primary megaureter & 1 & Catheter drainage \\
& 2 & Ureteric reimplantation \\
Duplex kidney with hydronephrosis & 1 & Conservative \\
Orthotopic ureterocele & 1 & Heminephroureterectomy \\
& & Ureteric reimplantation \\
\hline
\end{tabular}

second died when 28 days old despite relief of bladder outlet obstruction soon after birth. The third baby had unilateral renal dysplasia (and a normal contralateral kidney) but succumbed from a combination of congenital heart disease and a diaphragmatic hernia. Their treatment and that of the surviving 26 patients is summarised in Table 2. Twenty babies underwent a surgical procedure, all but six within one month of birth. All the surviving patients have serum creatinine concentrations within the normal range.

\section{Discussion}

Using current ultrasound equipment, the normal urinary tract is shown in over $80 \%$ of fetuses scanned from the 16th week of gestation onwards, ${ }^{2}$ while the chances of eliciting hydronephrotic or cystic lesions are of an even higher order. Later in pregnancy it is usually possible to make a precise diagnosis, and one which in many cases would not be clinically evident at birth, nor perhaps for months or years afterwards.

This expertise prompts two questions. Firstly, when, if ever, should prenatal intervention be attempted and secondly, what should be the management of those babies born at term without intervention? The first question is perhaps more easily answered. Very poor renal function may be suspected in the presence of oligohydramnios in conjunction with a fetal bladder which never fills or fails to refill after aspiration. ${ }^{1}$ Renal damage of this degree is almost always the consequence of severe obstruction to the urinary tract occurring early in pregnancy-often causing irreversible changes by the time it is detectable. ${ }^{3}$ The only realistic intervention that can be offered is termination of pregnancy. ${ }^{4} \mathrm{~A}$ more debatable situation is that where oligohydramnios is associated with bilateral renal amonalies but where some urine production may be found by observing the emptying and filling of the fetal bladder. These cases are comparatively uncommon and the diagnosis is usually that of posterior urethral valves. Long term intra-amniotic drainage of the fetal bladder has been advocated as a means of preserving (or even improving) whatever renal function exists and also to minimise pulmonary hypoplasia secondary to the oligohydramnios. ${ }^{1}$ Enthusiasts of this policy have yet to prove that it results in anything better than babies who are born with inadequate renal function or who drift into renal failure in later infancy.

In the absence of oligohydramnios, and especially when the renal disease is unilateral, there seems to be no justification for prenatal intervention. Although, in theory, obstructed renal tracts benefit 
Table 3 Benefits of prenatal ultrasound diagnosis in this series

\begin{tabular}{|c|c|c|c|c|c|}
\hline \multicolumn{2}{|l|}{ Definite benefit } & \multicolumn{2}{|l|}{ Probable benefit } & \multicolumn{2}{|l|}{ No benefit } \\
\hline Diagnosis & No & Diagnosis & No & Diagnosis & No \\
\hline \multirow{4}{*}{ Posterior urethral valves } & 1 & Multicystic or dysplastic kidney & 3 & Posterior urethral valves (both died) & 2 \\
\hline & & Primary megaureter & 3 & Dysplastic kidney and other anomalies (died) & 1 \\
\hline & & Duplex kidney with hydronephrosis & 1 & & \\
\hline & & Orthotopic ureterocele & 1 & & \\
\hline Totals & 6 & & 16 & & 7 \\
\hline
\end{tabular}

from drainage, in practice, the hazards of intervention outweigh any possible advantage.

Those babies born without undergoing any intervention (all except one in this series) may be considered in two categories. Firstly, the minority born with symptoms and signs of urinary tract disease. In the past these infants would ideally have been diagnosed soon after birth and treated appropriately. In practice detection was sometimes delayed for weeks or months, perhaps with adverse effects on renal function. In these cases prenatal ultrasound assessment is of definite benefit. In the second group -infants born without symptoms or signs of their anomaly - the benefits are less clearly defined. Many of the anomalies detected are comparatively minor and the natural history of these conditions is largely unknown. Extrapolation from experience with older children ${ }^{5}$ and adults indicates that the progress of pelviureteric junction obstruction or primary (obstructed) megaureter, for example, is often slow or even static, but this cannot be guaranteed. Nor is it possible to identify those at risk of sudden deterioration, although ultrasound does now enable regular, non-invasive monitoring of these lesions. It is not certain either how much can be expected of early surgical intervention. Neonatal pyeloplasty, for instance, gives good results ${ }^{5}$ but mainly in infants with gross degrees of hydronephrosis clearly requiring operation. Whether the effects of surgical treatment in kidneys with lesser degrees of obstruction will be so satisfactory remains to be seen. It is worth mentioning that not all dilated urinary tracts are necessarily obstructed and that surgical intervention is usually inadvisable. There are published reports of spontaneous resolution of hydronephrosis in neonates. ${ }^{6}$ Where there is any doubt, further investigation by diuresis renography or pressure-perfusion studies should be performed. ${ }^{78}$ Megacalicosis is an example of a dilated but non-obstructed upper urinary tract and is essentially a benign condition thought to represent 'burnt-out obstruction' that does not require active management. ${ }^{9}$ The role of surgery in the treatment of the multicystic or dysplastic kidney is an unresolved issue. ${ }^{10}$ In two of four such infants in this series the affected kidney was impalpable and only one of these had a nephrectomy (the other died as a neonate from gross cardiac anomalies). Prenatal detection is probably of benefit if for no other reason than that of the increased incidence of contralateral lesions. ${ }^{11}$

Bearing these considerations in mind, an attempt has been made in Table 3 to summarise the benefits of prenatal ultrasound in this series of patients. Taken overall, it was thought to be of advantage in most and detrimental to none. Whether in the long term the development of this technique will alleviate the burden of chronic renal failure is impossible to predict. Extravagant claims are unwise until experience is considerably increased and meanwhile assessment in specialist centres is to be encouraged so that guidelines for the future management of these infants may be formulated.

We would like to thank Messrs Johnston and Rickwood for allowing us to study their patients and for help and advice in the preparation of this paper.

\section{References}

1 Harrison MR, Golbus MS, Filly RA, et al. Fetal surgery for congenital hydronephrosis. $N$ Engl J Med 1982;306:591-3.

${ }^{2}$ Farrant $P$. Ultrasound diagnosis of fetal urinary obstruction. In: Lubec G, ed. Non-invasive diagnosis of kidney disease. Basel: Karger, 1983:297-314.

${ }^{3}$ Kramer SA. Current status of fetal intervention for congenital hydronephrosis. J Urol 1983;130:641-6.

${ }^{4}$ Campbell S, Pearce JM. The prenatal diagnosis of fetal structural anomalies by ultrasound. Clin Obstet Gynecol 1983;10:475-506.

5 Johnston JH, Evans JP, Glassberg KI, Shapiro SR. Pelvic hydronephrosis in children: a review of 219 personal cases. J Urol 1977;117:97-101.

6 Rickwood AMK. Transient ureteric dilatation in neonates with imperforate anus: a report of 4 cases. Br J Urol 1978;50:16-7.

7 Whitfield HN, Britton KE, Hendry WF, Nimmon CC, Whickham JEA. The distinction between obstructive uropathy and nephropathy by radioisotope transit times. $B r \quad J$ Urol 1978;50:433-6. 
${ }^{8}$ Whittaker RH. Methods of assessing obstruction in dilated ureters. Br J Urol 1973;45:15-22.

9 Johnston JH. Upper urinary tract obstruction, megacalicosis. In: Williams DI, Johnston JH, eds. Paediatric urology. 2nd ed. London: Butterworths, 1982:199-200.

${ }^{10}$ Bloom DA, Brosman S. The multicystic kidney. J Urol 1978;120:211-5.
1 Pathak IG, Williams DI. Multicystic and cystic dysplastic kidneys. Br J Urol 1964;36:318.

Correspondence to $\mathrm{Mr} \mathrm{R}$ Shawis, Department of Paediatric Surgery, Westminster Children's Hospital, Udall Street, Vincent Square, London SW1.

Received 24 April 1984

\section{Twenty five years ago}

Neurological sequelae of pertussis with particular reference to mental defect

\section{J M BERG (London)}

SUMmaRY A case is reported of a normal girl who developed whooping cough at 10 months. During the paroxysmal stage there were frequent periods of apnoea and neurological complications developed including drowsiness, twitching of the limbs, hypertonic extremities with brisk reflexes and transient internal strabismus. Screaming attacks and restlessness were also noted. Therapy included chloramphenicol and achromycin. The child survived the acute illness in a grossly demented state and suffering from fits, but without neurological localizing signs. At 31/12 years she was assessed to be of imbecile level. The condition is tentatively attributed to cerebral anoxia consequent on severe apnoea occurring during the paroxysmal stage of pertussis.

Neurological sequelae of pertussis, with particular reference to mental defect, are briefly considered.

(When advising doubtful parents about immunisation, we should explain to them that whooping cough may cause a nasty prolonged illness, and perhaps lung damage or brain damage, and that there is no satisfactory antibiotic or cough medicine which alters the clinical course. It is tragic that unwise propaganda about the so called dangers of immunisation should have caused so much suffering, scores of thousands of cases of whooping cough, thousands of hospital admissions, and many deaths. RONALD ILLINGWORTH) 